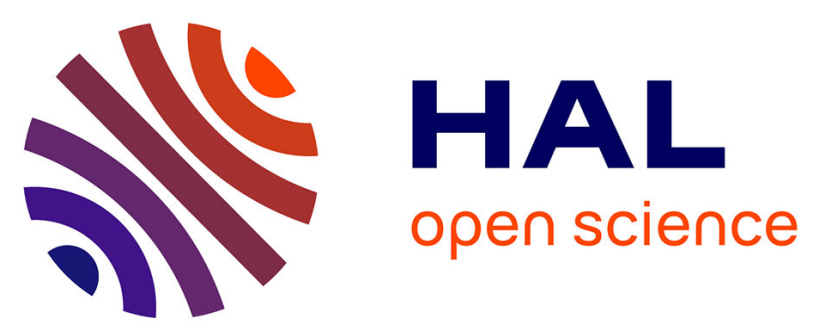

\title{
FIRST CASE OF SERRATED LESION OF THE DUODENAL PAPILLA IN A PATIENT WITH SERRATED COLONIC POLYPOSIS
}

Aymeric Becq, Jean-François Fléjou, Xavier Dray, Santiago Gimenez de Mestral, Marine Camus

\section{To cite this version:}

Aymeric Becq, Jean-François Fléjou, Xavier Dray, Santiago Gimenez de Mestral, Marine Camus. FIRST CASE OF SERRATED LESION OF THE DUODENAL PAPILLA IN A PATIENT WITH SERRATED COLONIC POLYPOSIS. Clinics and Research in Hepatology and Gastroenterology, 2021, 45 (3), pp.101484. 10.1016/j.clinre.2020.06.010 . hal-03263704

\section{HAL Id: hal-03263704 https://hal.sorbonne-universite.fr/hal-03263704}

Submitted on 17 Jun 2021

HAL is a multi-disciplinary open access archive for the deposit and dissemination of scientific research documents, whether they are published or not. The documents may come from teaching and research institutions in France or abroad, or from public or private research centers.
L'archive ouverte pluridisciplinaire HAL, est destinée au dépôt et à la diffusion de documents scientifiques de niveau recherche, publiés ou non, émanant des établissements d'enseignement et de recherche français ou étrangers, des laboratoires publics ou privés. 


\section{FIRST CASE OF SERRATED LESION OF THE DUODENAL}

\section{PAPILLA IN A PATIENT WITH SERRATED COLONIC \\ POLYPOSIS}

Aymeric Becq MD (1), Santiago Gimenez De Mestral MD (2), Marine Camus MD-PhD (1), Jean-François Fléjou MD-PhD (2), Xavier Dray MD-PhD (1)

1. Sorbonne Université, Endoscopy Unit, AP-HP, Hôpital Saint-Antoine, F-75012 Paris, France

2. Sorbonne Université, Pathology Department, AP-HP, Hôpital Saint-Antoine, F-75012 Paris, France

Correspondence to: Aymeric Becq, MD

Endoscopy Unit, Saint-Antoine Hospital, Paris, France

184 Rue du Faubourg Saint-Antoine, Paris, 75012

Tel: 01.71.97.08.43; Fax: 01.49.28.29.70

E-mail: aymeric.becq@aphp.fr

Conflicts of interest: Marine Camus is a consultant for Boston Scientific and Cook Medical. Xavier Dray is cofounder and shareholder of Augmented Endoscopy and has acted as a consultant for Alfasigma, Bouchara Recordati, Boston Scientific, Fujifilm, Medtronic, and Pentax. The other authors have no conflicts of interest to disclose.

This work was not sponsored by gifts or fellowships.

Keywords: Serrated polyposis, duodenal serrated lesion, screening endoscopy procedures 


\begin{abstract}
A serrated polyposis syndrome was diagnosed in a 26-year-old female presenting with gastrointestinal symptoms. Screening for other lesions of the gastrointestinal tract showed a serpiginous looking papilla, described as possibly dysplastic. Histological analysis of biopsies showed a serrated lesion. This case describes the first known association between a duodenal serrated lesion and serrated polyposis syndrome. Upper GI screening is probably of little interest in this setting. In patients with upper GI serrated lesions, we recommend screening colonoscopy.
\end{abstract}




\section{INTRODUCTION}

Serrated polyposis syndrome (SPS) is a colorectal polyp syndrome characterized by a combination of large and/or numerous serrated lesions, and is associated with an increased risk of colorectal cancer (CRC). Duodenal polyps have been described in the setting of colorectal polyp syndromes, but not in patients with SPS. We describe in this clinical case the first association between SPS and a duodenal serrated lesion.

\section{CASE PRESENTATION}

A 26-year-old female patient was initially referred for alternating diarrhea and constipation as well as intermittent abdominal pain. Past medical history was unremarkable. Physical examination was unremarkable. A colonoscopy was performed and showed multiple flat and sessile polyps, located throughout the different segments of the colon, ranging from 5 to 20 $\mathrm{mm}$ in diameter. The macroscopic aspect was compatible with serrated lesions as they presented with an irregular cloud-like surface, with black pits on some of them, and because a disruption of the vascular pattern of the surrounding colonic mucosa was noted (Figure 1A). Histological assessment confirmed these were sessile serrated lesions (SSL) with low-grade dysplasia (Figure 1B to 1G), establishing the diagnosis of SPS. After a multidisciplinary staff, resection of all the polyps located in the rectum and sigmoid colon was decided, before eventual subtotal colectomy. A complete endoscopic examination was performed in order to screen for other lesions of the gastrointestinal (GI) tract. Upper GI endoscopy and side-viewing duodenoscopy unexpectedly showed a serpiginous looking major papilla measuring $20 \mathrm{~mm}$ in length, described as possibly dysplastic (Figure 2A). Histological analysis of biopsies showed a serrated non-dysplastic lesion with the same immunophenotype as the colonic serrated adenomas/polyps (Figure 2B to 2F). Colonoscopy allowed resection of multiple polyps in the rectum and sigmoid colon. A subtotal colectomy with ileosigmoid anastomosis was 
subsequently performed. Analysis of the specimen confirmed multiple SSLs (about a hundred) and no cancerous lesion. The patient has undergone annual surveillance since. The last surveillance endoscopy was performed less than a year ago, with resection of three nondysplastic SSLs of the sigmoid colon and a similar endoscopic and histologic aspect of the major papilla. After they were all contacted, both parents and one of the five siblings of the patient underwent screening endoscopies (EGD, lateral duodenoscopy, and colonoscopy). All three family members had normal appearing major papillas. However, the father and one brother were diagnosed with SPS. A genetic testing is currently underway.

\section{DISCUSSION}

SPS has been defined by the World Health Organization (WHO) in 2010 as the presence of (1) $\geq 5$ histologically diagnosed serrated lesions proximal to the sigmoid colon, of which $\geq$ 2 are larger than $\geq 10 \mathrm{~mm}$; or (2) any number of serrated polyps proximal to the sigmoid colon in an individual who has a first-degree relative with SPS; or (3) $\geq 20$ serrated polyps distributed throughout the colon ${ }^{1}$. The true prevalence of SPS is unknown but it is likely underestimated, at $0.9 \%$ by recent studies ${ }^{2}$. The prevalence of CRC in this setting ranges between $15 \%$ and $35 \%{ }^{3,4}$. Given the risk of malignant progression, including during surveillance, endoscopic surveillance is recommended for all patients via colonoscopy every 1 to 2 years ${ }^{5,6}$.

Studies have evaluated whether SPS could harbor a risk of extracolonic polyposis or cancers. In a study published in 2013 including 44 patients with SPS, 22 patients had an esogastroduodenoscopy (EGD), with no lesion found ${ }^{7}$. In a cohort including 51 patients with SPS, published by Jasperson et al. in 2013, 30 patients had underwent an EGD, with no lesion found either ${ }^{8}$. There does not seem to be an extracolonic cancer risk either in patients with SPS 9,10. The British guidelines state that 'upper GI surveillance for polyposis or extraluminal 
surveillance for non-GI cancers is not necessary in patients with SPS where other genetic causes have been excluded' 5.

Regarding serrated lesions of the duodenum, data are scarce. The first case of duodenal SSL associated with a hereditary CRC syndrome (familial adenomatous polyposis) was published by Rubio et al. in $2004^{11}$. Several cases of duodenal serrated lesions have been published since, mostly of hyperplastic polyps ${ }^{12-14}$. A study by Cao et al. evaluated an endoscopy database of 98,746 patients. Serrated lesions of the upper GI tract where found in 21 patients $(0.02 \%)$ and 3 lesions were found in the duodenum only ${ }^{15}$. Overall, serrated lesions of the duodenum are rare, which accounts for the fact that their natural history and prognosis are unknown and the appropriate management unclear.

To our knowledge, the association between SPS and duodenal serrated lesions has not been reported so far. In the previously mentioned study by Cao et al., colonoscopy data were available for 18 of the 21 patients with upper GI serrated lesions and none had features of SPS although a higher colorectal adenoma detection rate was observed compared to patients with no upper GI serrated lesions ${ }^{15}$. We describe the first association between SPS and a duodenal serrated lesion (SSL). This case suggests that although extremely rare, patients with SPS can harbor upper GI lesions. However, based on the description of one case, we do not believe that EGD should be performed in patients with SPS in a systematic manner. However, there may be a subgroup of SPS patients in whom this screening might be of interest. Further studies are warranted to clarify the clinical significance of these lesions, such as genetic analysis to identify pathways associated with SPS. Conversely, based on the results of the study by Cao et al., we would recommend that patients with serrated lesions of the upper GI tract should undergo colonoscopy, as well as their first-degree relatives. 
In conclusion, we report the first case of a serrated lesion in the duodenum associated with SPS. Upper GI screening is probably of little interest in this setting. However, in patients with serrated lesions of the upper GI tract, we would recommend screening colonoscopy.

\section{FIGURES}

\section{Figure 1: Serrated lesion of the colon}

Endoscopic image in near focus and virtual chromoendoscopy (Narrow Band Imaging) showing a slightly elevated polyp located in the ascending colon (Paris IIa), with a maximal diameter of $10 \mathrm{~mm}$, an irregular cloud-like surface, with a few black pits (A). Histological assessment showed a distortion of the normal architecture (D, HE x 50) with dilated L-shaped or inverted T-shaped crypts and serrated glands (B, HE x 100). Serrated dysplastic areas were present (C, HE x 200). Immunohistochemical studies showed immunoreactivity for Annexin A10 (E, x 100), MUC2 (F, x 100) and MUC5AC (G, x 100). MLH1 expression was not lost (not shown).

\section{Figure 2: Serrated lesion of the duodenal papilla}

Endoscopic image in white light (A1) and virtual chromoendoscopy (Narrow Band Imaging) (A2) showing a serpiginous appearing papilla. Histological assessment showed a polypoid lesion (C, x 50) with slightly serrated epithelium without dysplasia (B, x 100). As the colonic serrated adenomas/polyps, immunoreactivity for Annexin A10 (E, x 100), MUC2 (F, x 100) and MUC5AC (G, x 100) was observed, and MLH1 expression was not lost (not shown).

\section{REFERENCES}


1. Bosman FT, Carneiro F, Hruban RH, Theise ND (Eds) WHO classification of tumours of the digestive system. IARC : Lyon 2010.

2. van Herwaarden YJ, Verstegen MHP, Dura P, et al. Low prevalence of serrated polyposis syndrome in screening populations: a systematic review. Endoscopy 2015; 47: 1043-1049.

3. Carballal S, Rodríguez-Alcalde D, Moreira L, et al. Colorectal cancer risk factors in patients with serrated polyposis syndrome: a large multicentre study. Gut 2016; 65: $1829-1837$.

4. IJspeert JEG, Rana S a. Q, Atkinson NSS, et al. Clinical risk factors of colorectal cancer in patients with serrated polyposis syndrome: a multicentre cohort analysis. Gut 2017; 66: $278-284$.

5. East JE, Atkin WS, Bateman AC, et al. British Society of Gastroenterology position statement on serrated polyps in the colon and rectum. Gut 2017; 66: 1181-1196.

6. Rex DK, Ahnen DJ, Baron JA, et al. Serrated lesions of the colorectum: review and recommendations from an expert panel. Am J Gastroenterol 2012; 107: 1315-1329; quiz 1314, 1330.

7. Edelstein DL, Axilbund JE, Hylind LM, et al. Serrated polyposis: rapid and relentless development of colorectal neoplasia. Gut 2013; 62: 404-408.

8. Jasperson KW, Kanth P, Kirchhoff AC, et al. Serrated polyposis: colonic phenotype, extracolonic features, and familial risk in a large cohort. Dis Colon Rectum 2013; 56: 1211-1216.

9. Hazewinkel Y, Reitsma JB, Nagengast FM, et al. Extracolonic cancer risk in patients with serrated polyposis syndrome and their first-degree relatives. Fam Cancer 2013; 12 : $669-673$.

10. Win AK, Walters RJ, Buchanan DD, et al. Cancer risks for relatives of patients with serrated polyposis. Am J Gastroenterol 2012; 107: 770-778.

11. Rubio CA. Serrated adenoma of the duodenum. J Clin Pathol 2004; 57: 1219-1221.

12. Iwamuro M, Hori K, Tanaka T, et al. Serrated polyp of the duodenum. Gastrointest Endosc 2015; 82: 966-967; discussion 967.

13. Sarbia M, Jüttner S, Bettstetter M, et al. [Serrated polyps of the duodenum. Three cases with immunohistological and molecular pathological findings]. Pathol 2013; 34: 347351.

14. Rosty C, Campbell C, Clendenning M, et al. Do serrated neoplasms of the small intestine represent a distinct entity? Pathological findings and molecular alterations in a series of 13 cases. Histopathology 2015; 66: 333-342.

15. Cao H-L, Dong W-X, Xu M-Q, et al. Clinical features of upper gastrointestinal serrated lesions: An endoscopy database analysis of 98746 patients. World J Gastroenterol 2016; 22: $10038-10044$. 


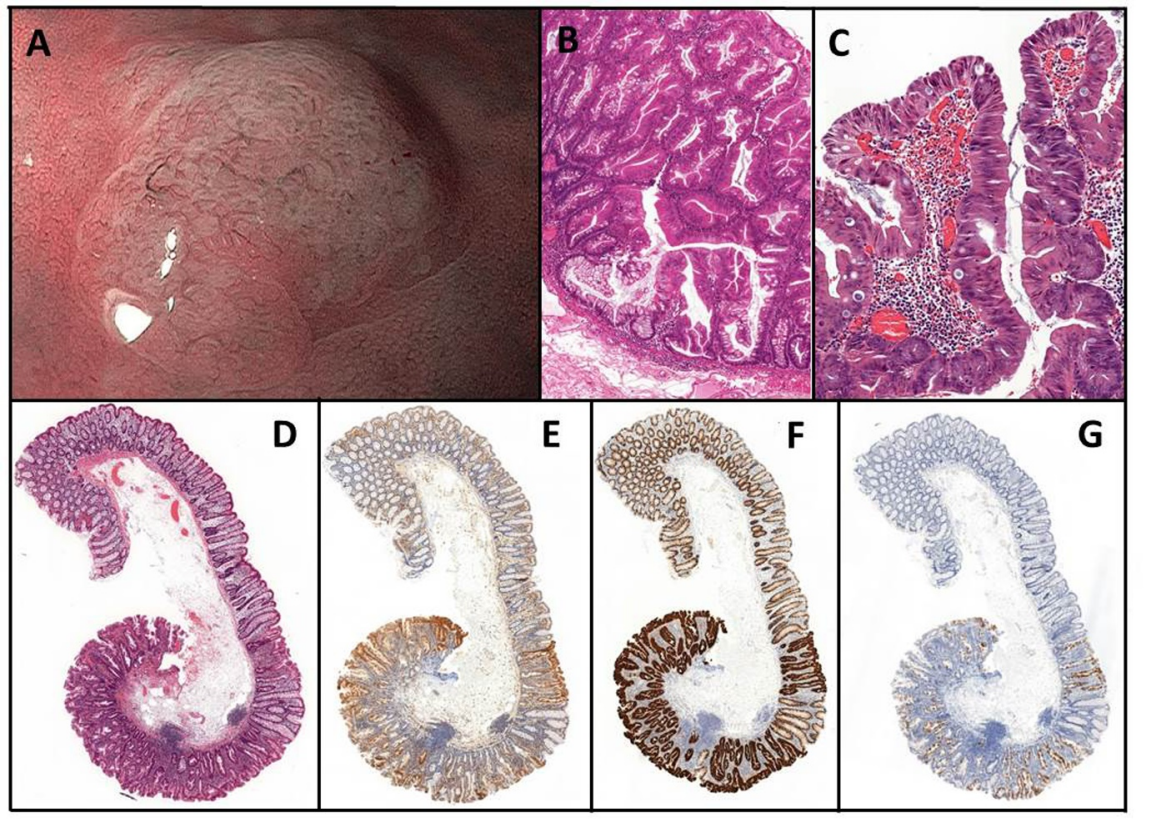




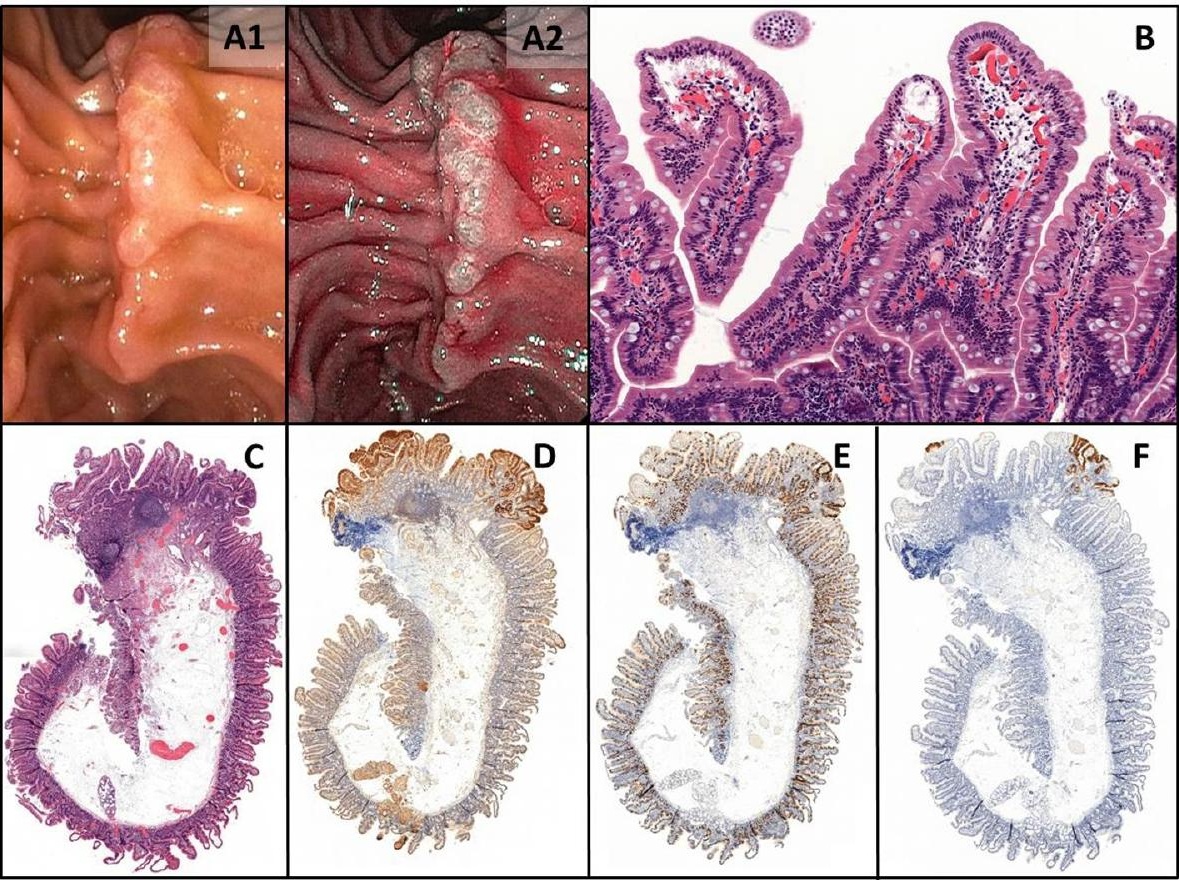

